\title{
Spatio-temporal comparison of Pacific white-sided dolphin echolocation click types
}

\author{
Melissa S. Soldevilla ${ }^{1,2, *}$, Sean M. Wiggins ${ }^{1}$, John A. Hildebrand ${ }^{1}$ \\ ${ }^{1}$ Scripps Institution of Oceanography, University of California, San Diego, 9500 Gilman Dr. \#0205, La Jolla, \\ California 92093-0205, USA \\ ${ }^{2}$ Present address: Duke University Marine Lab, 135 Duke Marine Lab Road, Beaufort, North Carolina 28516, USA
}

\begin{abstract}
A comparison of temporal and geographical trends in different echolocation click types produced by Pacific white-sided dolphin Lagenorhynchus obliquidens can lead to insights into the significance of their usage by the dolphins. Using autonomous seafloor recording packages, the spatial, diel and seasonal patterns of Pacific white-sided dolphin echolocation click activity are described for 6 locations in the Southern California Bight. Click bouts of the 2 types of Pacific white-sided dolphin echolocation clicks are identified based on their unique spectral characteristics in long-term spectral averages. Type A clicks were detected on 317 of 1959 recording days and were heard at all 6 sites, with the majority of detections occurring at San Clemente Island and Point Conception. Type B clicks were detected on 130 recording days and were only heard at the 2 southern inshore sites. Significant diel patterns were evident for both click types: Type A click bouts were detected during more hours and with higher click rates at night than during the day, while Type B click bouts exhibited the opposite behavior, with greater activity during the day. At the southern sites, both click types exhibited a fall-winter peak in seasonal occurrence. At Point Conception, where only Type A was detected, peak occurrence was during spring. The described spatial and seasonal patterns support the hypothesis that click types are population-specific, while diel patterns suggest differences in prey preferences.
\end{abstract}

KEY WORDS: Pacific white-sided dolphin · Lagenorhynchus obliquidens · Passive acoustic monitoring $\cdot$ Southern California Bight $\cdot$ Echolocation $\cdot$ Diel $\cdot$ Seasonality

\section{INTRODUCTION}

Pacific white-sided dolphins Lagenorhynchus obliquidens are a cold-temperate pelagic species endemic to the North Pacific Ocean. They are found in the Sea of Japan, the southern Bering Sea and along the west coast of North America as far south as the Gulf of California (Leatherwood et al. 1984). Offshore of California, they are the fifth most abundant cetacean species (Barlow \& Forney 2007), often found in large schools and in association with other cetacean species. Two genetically and morphometrically distinct populations occupy the Southern California Bight (SCB), of which a northern California/Oregon/Washington population occurs northward of $33^{\circ} \mathrm{N}$ and a southern Baja Califor- nia population occurs southward of $36^{\circ} \mathrm{N}$, with overlap in the 2 populations' ranges occurring between $33^{\circ}$ and $36^{\circ} \mathrm{N}$ (Walker et al. 1986, Lux et al. 1997). These 2 populations are not visually distinguishable in the field and it remains unknown whether the 2 populations exist sympatrically or occupy the region at different times seasonally or annually (Carretta 2004). Pacific white-sided dolphins forage opportunistically on abundant epipelagic and mesopelagic schooling fish and cephalopods (Stroud et al. 1981).

Seasonal movement patterns of Pacific white-sided dolphins have been studied using ship-based and aerial visual survey methods. Along the west coast of North America, abundance and distribution of Pacific white-sided dolphins are highly variable on both sea- 
sonal and annual time scales (Shane 1994, Benson et al. 2002, Barlow \& Forney 2007). Four conflicting seasonal movement patterns have been hypothesized: (1) inshore movements in winter/spring and offshore movements in summer/fall (Brown \& Norris 1956, Norris \& Prescott 1961, Roest 1970, Dohl et al. 1983, Black 1994); (2) south-north movements between California in winter/spring and Oregon/Washington in summer/fall (Green et al. 1992, Forney \& Barlow 1998); (3) south-north movements between southern California in winter/spring and central California in summer/ fall (Black 1994); and (4) north-south movements between southern California in winter/spring and Baja California, Mexico in summer/fall (Leatherwood et al. 1984). Some authors suggest seasonal and interannual movements are related to large-scale temperature changes (Leatherwood et al. 1982, 1984, Dohl et al. 1983, Benson et al. 2002). These seasonal movement hypotheses are not necessarily mutually exclusive and do not distinguish the seasonal movements of the 2 populations found in this region.

On a shorter temporal scale, it has not been possible to study Pacific white-sided dolphin diel behavioral patterns using visual techniques, as the animals cannot be seen at night. A visual survey conducted off Monterey during daylight hours indicates that foraging, milling, resting and traveling behaviors do not exhibit a daily cycle (Black 1994). Numerous lines of evidence indicate that foraging occurs throughout both day and night: direct visual observation (Brown \& Norris 1956, Black 1994, Morton 2000), prey sampling (Heise 1997), radio-tagging (Leatherwood \& Evans 1979, Black 1994) and purse-seine net bycatch (Walker et al. 1986) have identified daytime foraging activity; and stomach content analyses (Stroud et al. 1981) and purse-seine net bycatch (Walker et al. 1986) have been used to detect nighttime foraging.

Passive acoustic monitoring is an alternate survey technique that can be used to examine seasonal movement patterns and diel behavioral trends of vocalizing animals. Recent spectral analyses of the echolocation clicks of Pacific white-sided dolphins off southern California has revealed the existence of 2 distinct echolocation click types (Soldevilla et al. 2008) that can be readily distinguished from other species and from each other. The biological significance of the 2 click types remains unknown, but they may correspond to the 2 distinct populations revealed by genetic and morphologic studies (Soldevilla et al. 2008). While no studies have linked free-ranging Pacific white-sided dolphin click usage with behavior state, concurrent behavioral and acoustical studies of numerous other odontocetes indicate higher click rates and occurrence during foraging behaviors, moderate click rates during traveling and socializing behaviors and low click rates and occurrence during resting behaviors (Hawaiian spinner dolphins Stenella frontalis: Norris et al. 1994, killer whales Orcinus orca: Barrett-Lennard et al. 1996, Pacific humpback dolphins Sousa chinensis: Van Parijs \& Corkeron 2001, bottlenose dolphins Tursiops truncatus: Nowacek 2005). Assuming similar patterns for Pacific white-sided dolphin behavior and click activity, the variability in recorded click rates and occurrence can be used to differentiate periods of activity and rest. In addition, echolocation clicks, produced during daily foraging (Smith \& Gaskin 1974, Lockyer 1981, Au 1993), are an ideal call type for examining seasonal occurrence throughout an area; comparisons of echolocation clicks across sites allow investigation of seasonal movement patterns.

Autonomous, fixed-sensor, acoustic-based surveys offer a monitoring technique that can be used for surveying dolphin activity and geographical movements over long periods, in remote locations, during adverse weather conditions and during nighttime periods. Species-specific Pacific white-sided dolphin echolocation clicks can be used to examine seasonal movement patterns and diel behavioral patterns. A comparison of the similarities and differences in the spatial and temporal occurrence of the 2 Pacific white-sided dolphin click types may lead to insights into the significance of the 2 click types as well as the ecology of Pacific whitesided dolphins in the SCB. The present study used long-term passive acoustic recordings to examine spatial and temporal trends in Pacific white-sided dolphin echolocation behavior and movement patterns. To determine if Pacific white-sided dolphins exhibit variability in diel activity levels and consistent seasonal movements in the $\mathrm{SCB}$, we examined $2.5 \mathrm{yr}$ of data from autonomous seafloor recording packages at 6 sites throughout the SCB for the occurrence of Pacific white-sided dolphin echolocation click bouts. Click bout occurrence and click rates were compared between periods of daylight and darkness, and diel and seasonal trends in echolocation behavior were described and compared between the 2 click types. The implications for foraging, movements and the significance of click types are discussed.

\section{MATERIALS AND METHODS}

Instrumentation and data collection. High-frequency acoustic recording packages (HARPs) were deployed at 6 locations throughout the SCB between August 2005 and December 2007 at depths ranging between 300 and $1330 \mathrm{~m}$ (Fig. 1). A brief description of these autonomous seafloor-mounted acoustic recorders is provided here for clarity; see Wiggins \& Hildebrand (2007) for a detailed description of HARP design and 


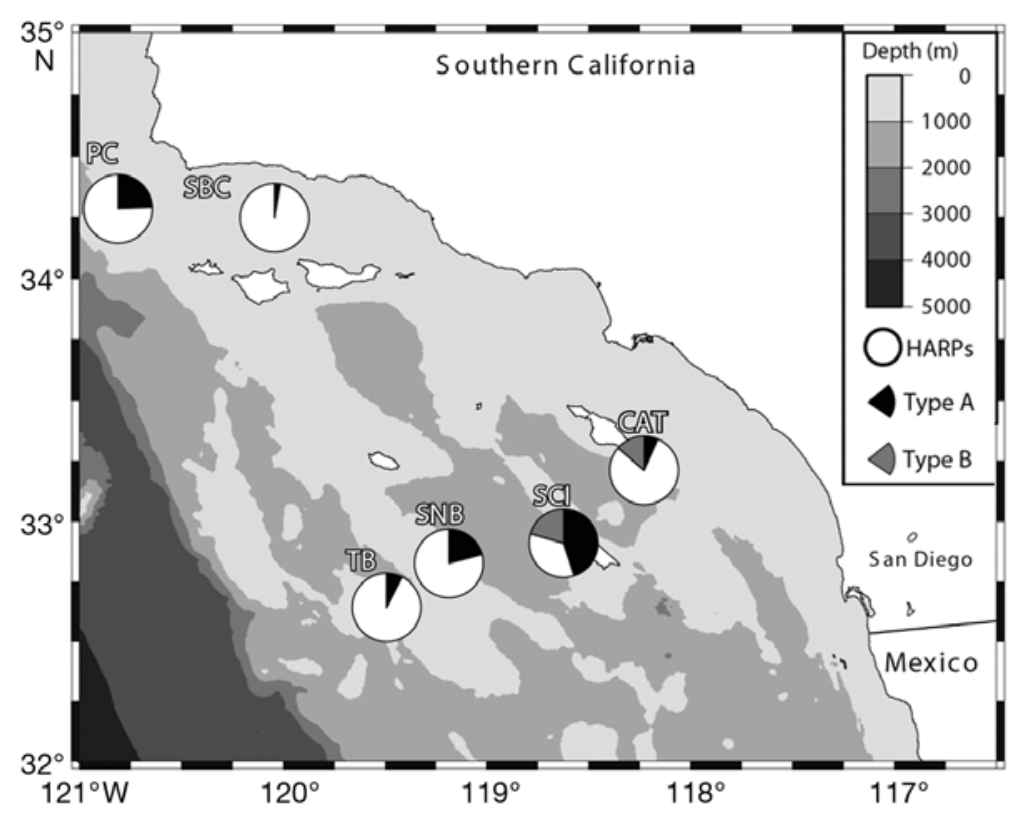

Fig. 1. Study area, including locations of High-frequency Acoustic Recording Package (HARP) deployments. PC: Point Conception; SBC: Santa Barbara Channel; TB: Tanner Basin; SNB: San Nicholas Basin; SCI: San Clemente Island; CAT: Santa Catalina Island. HARP locations are presented as pie charts in which the black and gray areas indicate the percentage of recording days with Pacific white-sided dolphin Types A and B click bouts present, respectively. Type A clicks were heard throughout the region, while Type B clicks were only heard at the 2 southern inshore sites (SCI and CAT). The 2 click types may occur on the same day; therefore, at these 2 sites, the white area represents a minimum percentage of days with no Pacific white-sided click bouts identified

capabilities. The HARP data-logging system includes a 16 bit A/D converter, up to $1.9 \mathrm{~TB}$ of storage capacity, a hydrophone suspended $10 \mathrm{~m}$ above the seafloor, a release system, ballast weights and flotation. The hydrophone and preamplifiers have $30 \mathrm{~Hz}$ to $100 \mathrm{kHz}$ bandwidth with a pre-whitened frequency response designed to follow the reciprocal of ambient ocean noise (Wiggins \& Hildebrand 2007). The dataloggers are capable of sampling up to $200 \mathrm{kHz}$ and can be set to record continuously or on a sampling schedule to accommodate variable deployment durations. The present study includes data from 30 HARP deployments each lasting from 1 to $4 \mathrm{mo}$ in duration. Temporal coverage at each of the 6 sites was variable due to research vessel availability and occasional instrument problems (Table 1). Data from all deployments included in the present study were sampled at $200 \mathrm{kHz}$, resulting in a recording bandwidth of $30 \mathrm{~Hz}$ to $100 \mathrm{kHz}$. A variety of sampling schedules were used across deployments, with two-thirds of deployments recorded on a continuous sampling schedule and the remaining one-third recorded on a sampling schedule of $5 \mathrm{~min}$ on followed by 5, 10 or $15 \mathrm{~min}$ off for a given deployment (Fig. 2).

Click bout detection. Acoustic data were analyzed with a custom software program, Triton, developed in MATLAB (MathWorks). Raw acoustic HARP data were converted to XWAV format, a format similar to WAV format, that incorporates instrument metadata in an expanded header file, including recording start and stop times. This timing information is crucial when analyzing non-continuous data. Each HARP deployment resulted in 1.6 to $1.9 \mathrm{~TB}$ of data which is impractical to analyze manually in original form. Therefore, these data were compressed for visual overview by creating longterm spectral averages (LTSAs, Wiggins \& Hildebrand 2007) from the XWAV files. LTSAs are effectivelycompressed spectrograms created using the Welch algorithm (Welch 1967) by coherently averaging 500 spectra created from 2000-point, $0 \%$-overlapped, Hann-windowed data and displaying these averaged

Table 1. Seasonal recording effort (number of week-long replicate samples available for statistical analysis at each site for each season of each year) at each site across 3 yr of study. See Fig. 1 for site abbreviations. TB and SNB are not included in the total samples for the seasonal analysis because they were deployed during only part of the year in 2007 and did not sample across all seasons

\begin{tabular}{|c|c|c|c|c|c|c|c|c|c|c|c|c|c|}
\hline \multirow[b]{2}{*}{ Site } & \multicolumn{3}{|c|}{ Winter (Jan-Mar) } & \multicolumn{3}{|c|}{ Spring (Apr-Jun) } & \multicolumn{3}{|c|}{ Summer (Jul-Sep) } & \multicolumn{3}{|c|}{ Autumn (Oct-Dec) } & \multirow{2}{*}{ Total } \\
\hline & 2005 & 2006 & 2007 & 2005 & 2006 & 2007 & 2005 & 2006 & 2007 & 2005 & 2006 & 2007 & \\
\hline $\mathrm{PC}$ & 0 & 3 & 10 & 0 & 0 & 13 & 7 & 5 & 13 & 13 & 4 & 3 & 71 \\
\hline SBC & 0 & 4 & 8 & 0 & 0 & 3 & 7 & 0 & 12 & 13 & 7 & 5 & 59 \\
\hline TB & 0 & 0 & 0 & 0 & 0 & 4 & 0 & 4 & 13 & 0 & 3 & 3 & 27 \\
\hline SNB & 0 & 0 & 0 & 0 & 0 & 0 & 0 & 0 & 7 & 0 & 0 & 7 & 14 \\
\hline SCI & 0 & 0 & 11 & 0 & 0 & 12 & 0 & 0 & 9 & 0 & 0 & 8 & 40 \\
\hline CAT & 0 & 4 & 8 & 0 & 0 & 9 & 7 & 12 & 10 & 13 & 12 & 10 & 85 \\
\hline \multicolumn{14}{|l|}{ Total } \\
\hline Season & 0 & 11 & 37 & 0 & 0 & 37 & 21 & 17 & 44 & 39 & 23 & 26 & 255 \\
\hline $3 \mathrm{yr}$ & & 48 & & & 37 & & & 82 & & & 88 & & 255 \\
\hline
\end{tabular}




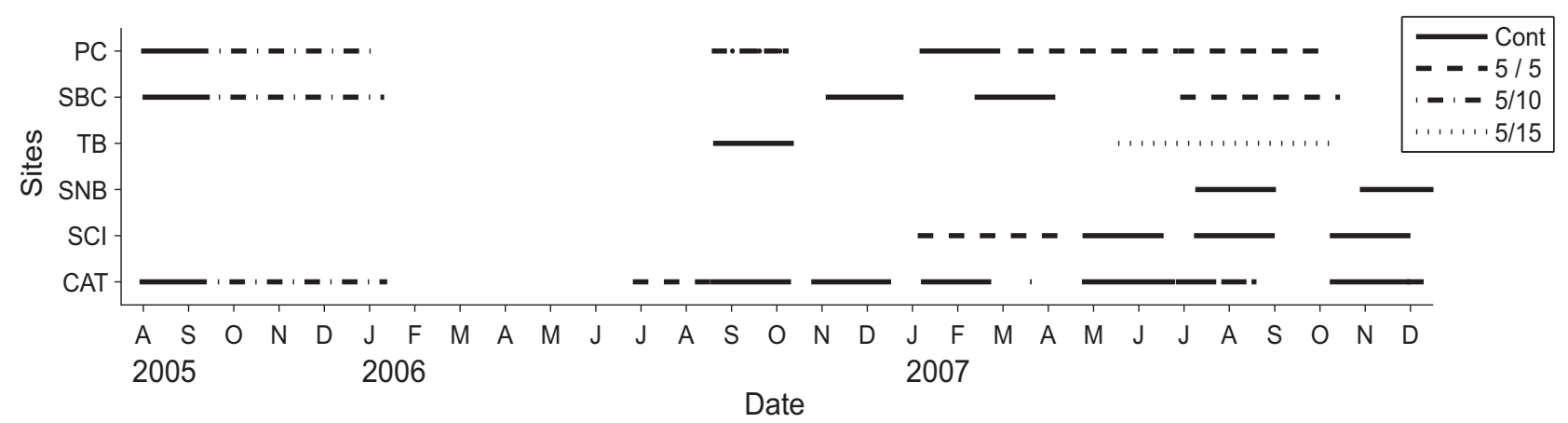

Fig. 2. High-frequency Acoustic Recording Package data availability and sampling schedule at each of 6 sites in the Southern California Bight. See Fig. 1 for site abbreviations. Data availability is indicated by presence of a line at each site while sampling schedule (continuous, $5 \mathrm{~min}$ on/5 $\mathrm{min}$ off, $5 \mathrm{~min}$ on/10 $\mathrm{min}$ off, $5 \mathrm{~min}$ on/15 min off) is indicated by line type

spectra sequentially over time. The resulting LTSAs had resolutions of $100 \mathrm{~Hz}$ and $5 \mathrm{~s}$ in frequency and time, respectively. Using LTSAs with this resolution, delphinid whistling and echolocation clicking bouts, rain bouts, ship passings and other acoustic phenomenon can easily be distinguished from background noise (e.g. Wiggins \& Hildebrand 2007), allowing an efficient review of these large data sets. An experienced acoustician can review and annotate a complete HARP data set, approximately $1300 \mathrm{~h}$ of data, in approximately $16 \mathrm{~h}$.

Soldevilla et al. (2008) describe 2 distinct click types based on unique spectral patterns found in individual echolocation clicks of Pacific white-sided dolphins recorded during concurrent visual and acoustic ship- based surveys. Click type A can be identified by spectral peaks at 22, 27.5 and $39 \mathrm{kHz}$ with spectral notches at $19,24.5$ and $30 \mathrm{kHz}$. Click type B can be identified by spectral peaks at 22, 26 and $37 \mathrm{kHz}$ with spectral notches at 19, 24 and $30 \mathrm{kHz}$. These 2 click types are easily distinguished from those of other species commonly found offshore of southern California. The presence of unique spectral banding patterns clearly distinguishes this species from short-beaked common dolphins Delphinus delphis, long-beaked common dolphins D. capensis and bottlenose dolphins, while the existence of a spectral notch around $30 \mathrm{kHz}$ as opposed to a peak distinguishes them from Risso's dolphins Grampus griseus (Soldevilla et al. 2008). These spectral patterns are found in many echolocation click
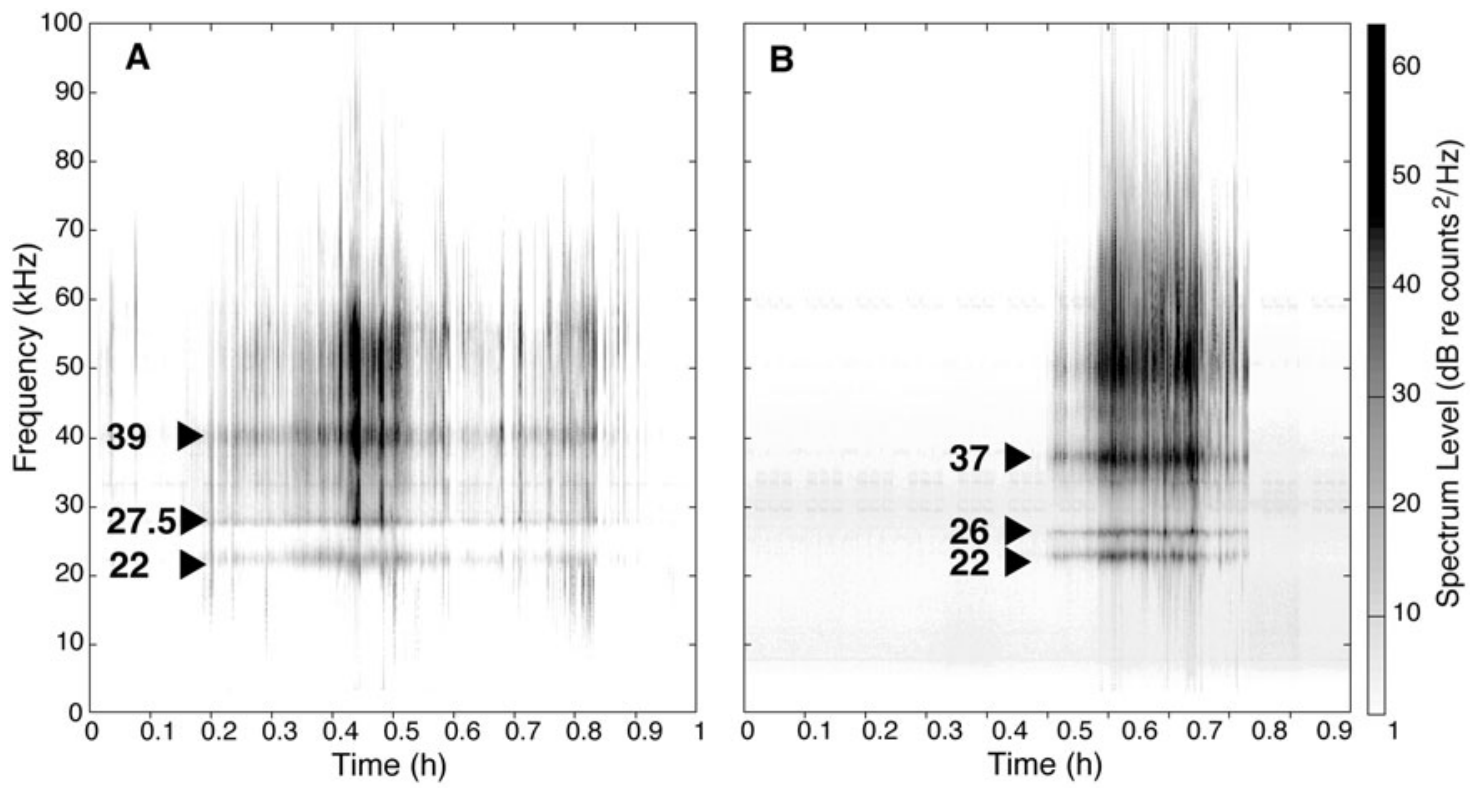

Fig. 3. Example long-term spectral average illustrating echolocation click bouts containing the unique spectral peak and notch structure of the 2 Pacific white-sided dolphin click types described by Soldevilla et al. (2008). LTSA spectrogram has resolutions of $100 \mathrm{~Hz}$ and $5 \mathrm{~s}$ in frequency and time, respectively, and represents coherent averages of 500 spectra created using 2000 point, $0 \%$ overlapped, Hann-windowed High-frequency Acoustic Recording Package data. Spectral peaks occur at approximately 22, 27.5 and $39 \mathrm{kHz}$ in Type A clicks and at approximately 22, 26 and $37 \mathrm{kHz}$ in Type B clicks 
bouts in autonomously recorded HARP data and are particularly striking as visualized in LTSAs (Fig. 3). By visually examining 30 min LTSA segments, the start and end times of click bouts exhibiting the described spectral patterns were identified and logged. All LTSAs were reviewed by a single acoustician throughout the $2.5 \mathrm{yr}$ study period. Therefore, inter-observer variability is not expected to influence results; however, intra-observer variability as experience increased over time could have had effects. To ensure consistent analysis, all data collected prior to December 2006 were reanalyzed during 2007.

Pacific white-sided dolphins may occur in mixedspecies groups with the other delphinid species which occur offshore of southern California. Occasionally, click bouts without spectral banding patterns or with Risso's dolphin spectral patterns overlapped Pacific white-sided dolphin click bouts, or the 2 Pacific whitesided dolphin click types occurred together. These bouts were labeled as mixed groups. Click bout start and end times were used to calculate daily occurrence, hourly occurrence and click rates for temporal analyses. Mixed group data were only included in temporal analyses of Pacific white-sided dolphin click occurrence and were removed from the remaining click rate analyses, as described below.

Individual click detection. To calculate click rates for analysis of diel patterns, clicks were automatically detected using the algorithm described in Soldevilla et al. (2008). While the click detector can automatically detect clicks, it cannot automatically classify them to species. Therefore, individual click classifications were determined from the LTSA click bout classifications described previously. All detected clicks which occurred within start and end times of visually classified LTSA Pacific white-sided dolphin click bouts were classified as Type A or Type B. By requiring both manual detection of the click bouts and automatic detection of individual clicks within these bouts, the false alarm rate was found to be very low from general inspection. Individual detected clicks that occurred in mixed-group click bouts were not included in the diel click rate portion of the analysis because they could not be automatically assigned to click type. Removal of this data is not expected to bias diel click rate analysis, as mixedgroups accounted for only 18 and $11 \%$ of the hourly Pacific white-sided dolphin Types A and B click bout occurrences, respectively, and no diel trend in occurrence was apparent for the removed data.

Diel and seasonal analysis. Both hourly click bout occurrence and click rate data were examined for diel patterns. At each site, daily sunrise, sunset and twilight data were obtained from the US Naval Observatory (2008) online database to establish light and dark periods. Day and night were defined as the periods between nautical twilight, when the sun altitude was at $-12^{\circ}$ from the horizon. Each click bout was assigned to either day or night. Click bouts that spanned multiple periods were segmented and each segment was assigned the appropriate light or dark period.

To examine diel variation in hourly click bout occurrence, ones and zeros were assigned to $1 \mathrm{~h}$ interval bins indicating presence or absence, respectively. Seasonal variation in duration of day and night periods was normalized by dividing the number of $1 \mathrm{~h}$ bins with clicks present per period per day by the total number of $1 \mathrm{~h}$ bins per period per day. Bins that crossed boundaries between periods were assigned to the period that contained the greater portion of the hour. ANOVA was used to test whether variability in percentage of hours with clicks was significantly different between day and night periods (Zar 1999).

To examine diel variation in Pacific white-sided dolphins click rates, click rates were calculated as the number of clicks detected divided by the total recording duration in minutes for each light and dark period of each day. To account for shorter recording durations caused by the sampling schedule, total recording duration was calculated from recording start times and durations stored in the XWAV header files. Variability between days was accounted for by calculating a mean-adjusted calling rate in which the daily click rate was subtracted from the click rate for each light and dark period for each day. ANOVA was used to test whether variability in click rates was significantly different between day and night periods (Zar 1999).

To examine seasonal variation in click bout occurrence, the total number of days with click detections present per week was calculated and compared across seasons, sites and years. Seasons were defined by quarters of the year and, since seasonal effort across years and sites was variable (Table 1), data were included only from sites with complete seasonal coverage. The 2 northern inshore sites (Point Conception and Santa Barbara Channel) and the 2 southern inshore sites (Santa Catalina Island and San Clemente Island) met the criteria for inclusion as they sampled all 4 seasons, while data from the 2 southern offshore sites (Tanner Basin and San Nicolas Basin) did not (Table 1). The total number of days with click detections present per week was chosen to minimize bias caused by differences in sampling effort across sites and seasons. Presence at $1 \mathrm{~d}$ resolution was chosen to minimize the bias due to sampling schedule as the mean probability of detecting presence on a given day for Type A clicks was 99, 96 and $93 \%$ and for Type B clicks was 100, 100 and $98 \%$ for sampling schedules of $5 \mathrm{~min}$ on and 5,10 and 15 min off, respectively (Soldevilla 2008). These high daily probabilities are a result of long click bout durations (often greater than $15 \mathrm{~min}$ ) and short inter- 

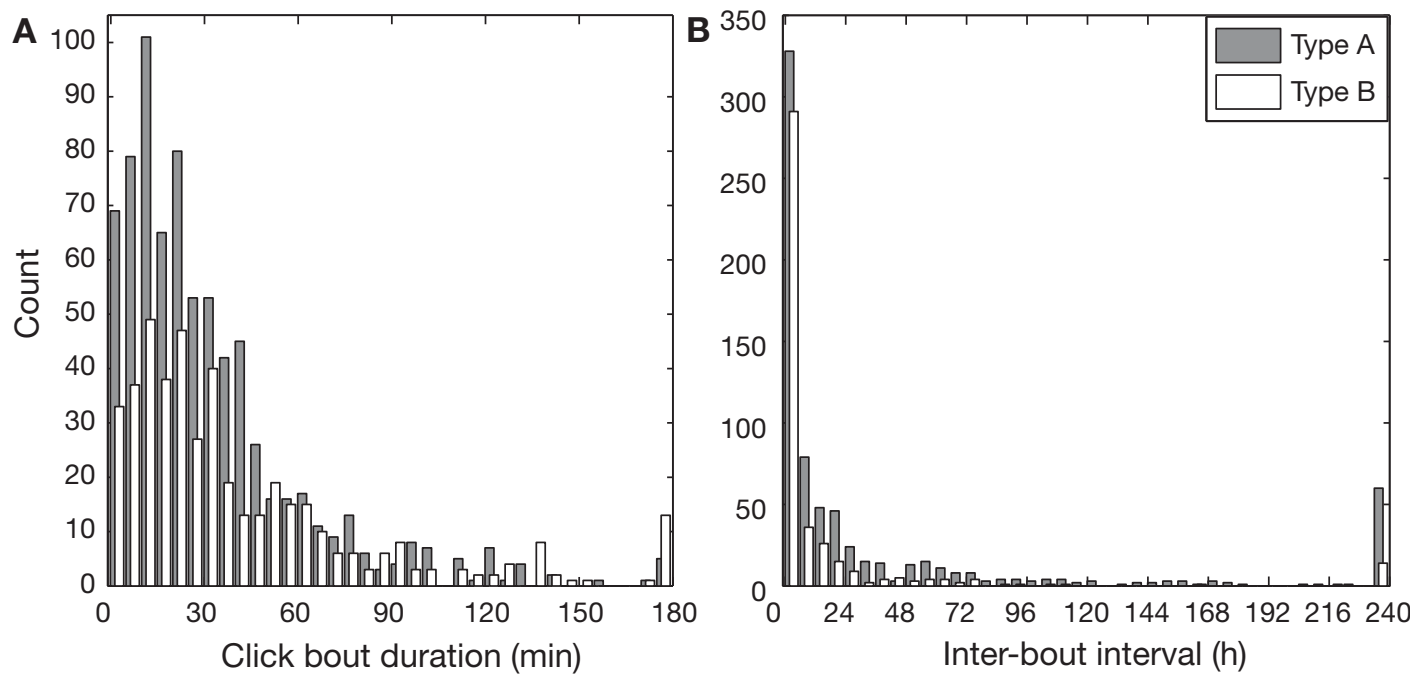

Fig. 4. Pacific white-sided dolphin (A) click bout durations and (B) inter-bout intervals for each click type from continuously sampled High-frequency Acoustic Recording Package recordings. Histogram tails extend further to the right and have been lumped into the last bin for easier viewing

bout intervals $(<1$ d) (Fig. 4). Weeks were chosen for the sample duration to provide a reasonable number of replicates per season, site and year, and because $83 \%$ of 255 week-long samples contained 7 complete days of recording effort. The remaining samples were normalized by the number of recording days to account for reduced effort. While this metric ensured that effort was comparable across samples, the number of replicate samples per season, site and year varied (Table 1), requiring the use of a statistical test that accounts for the unbalanced design. Therefore, the null hypotheses of equal means across seasons, years and sites and possible interactions between these variables were tested using the Generalized Linear Model (GLM) ANOVA function in SPSS 11.5 (www.spss.com) with 3-way full factorial design and Type IV sum of squares to account for the unbalanced design (Table 1). An ANOVA can only test if all means are equal; Tamhane's T2 post hoc test was used to determine which seasons, sites or years were different (Zar 1999, Garson 2008).

\section{RESULTS}

\section{Geographical variation}

About 2000 recording days including over $45500 \mathrm{~h}$ of data were analyzed from instruments at the 6 locations in the SCB, with the majority of effort at the Santa Catalina Island, Santa Barbara Channel, Point Con-

Table 2. Summary of number of days and hours with recording effort, number of days and hours with Pacific white-sided dolphin Types A and B click bouts present (n), percentage of days and hours with Types A and B click bouts present and mean instrument depth at each of the 6 High-frequency Acoustic Recording Package sites. See Fig. 1 for site abbreviations

\begin{tabular}{|c|c|c|c|c|c|c|c|c|c|c|c|}
\hline \multirow[t]{2}{*}{ Site } & \multicolumn{2}{|c|}{ Recording effort } & \multicolumn{4}{|c|}{ Type A present } & \multicolumn{4}{|c|}{ Type B present } & \multirow{2}{*}{$\begin{array}{l}\text { Instrument } \\
\text { depth } \\
\text { (m) }\end{array}$} \\
\hline & (d) & (h) & (d) & (h) & (d) & $(\mathrm{h})$ & (d) & (h) & (d) & (h) & \\
\hline \multicolumn{12}{|c|}{ Northern } \\
\hline $\mathrm{PC}$ & 457 & 10499 & 112 & 307 & 24.5 & 0.7 & 0 & 0 & 0 & 0 & 787 \\
\hline SBC & 377 & 8753 & 10 & 21 & 2.7 & 0.2 & 0 & 0 & 0 & 0 & 585 \\
\hline \multicolumn{12}{|c|}{ Southern offshore } \\
\hline TB & 199 & 4647 & 15 & 28 & 7.5 & 0.6 & 0 & 0 & 0 & 0 & 1316 \\
\hline SNB & 110 & 2469 & 23 & 48 & 20.9 & 1.9 & 0 & 0 & 0 & 0 & 1013 \\
\hline \multicolumn{12}{|c|}{ Southern inshore } \\
\hline SCI & 266 & 6277 & 120 & 433 & 45.1 & 6.7 & 55 & 257 & 20.7 & 4.1 & 435 \\
\hline CAT & 550 & 12862 & 37 & 93 & 6.7 & 0.7 & 75 & 343 & 13.6 & 2.7 & 351 \\
\hline Total & 1959 & 45507 & 317 & 930 & 16.2 & 2.0 & 130 & 600 & 6.6 & 1.3 & - \\
\hline
\end{tabular}


ception and San Clemente Island sites (Table 2). Pacific white-sided dolphin Type A clicks were identified at all 6 locations on a total of 317 recording days (16\% of all days) and in 930 recording hours (2\% of all hours) (Fig. 1, Table 2). They were identified most often at San Clemente Island and Point Conception where click bouts were identified on 45 and $25 \%$ of days and 7 and $3 \%$ of hours, respectively. While Type A clicks were identified on $21 \%$ of days and $2 \%$ of hours at San Nicholas Basin, this may be a biased estimate as this instrument only recorded during one-third of the year and seasonal variations may have been missed. At the remaining sites, Type A clicks were identified between 2 and $8 \%$ of days and 0.2 and $1 \%$ of hours. Pacific white-sided dolphin Type B clicks were identified only at the 2 southern inshore sites for a total of 130 recording days ( $7 \%$ of all days) and 600 recording hours (1.3\% of all hours) (Fig. 1, Table 2). At Santa Catalina and San Clemente Islands, Type B clicks were identified between 14 and $21 \%$ of days and 3 and $4 \%$ of hours; they were not identified at the northern sites in over 800 recording days, or at the southern offshore sites in over 300 recording days. The 2 click types clearly exhibit distinct geographical occurrence patterns in which type $\mathrm{A}$ is heard throughout the region while type B is only heard at the southern inshore sites (Fig. 1, Table 2).

\section{Diel variation}

A distinct diel pattern was evident in the occurrence of Pacific white-sided dolphin Type A echolocation click bouts across hours of the day. Across all sites, Type A click bouts occurred most frequently at night,

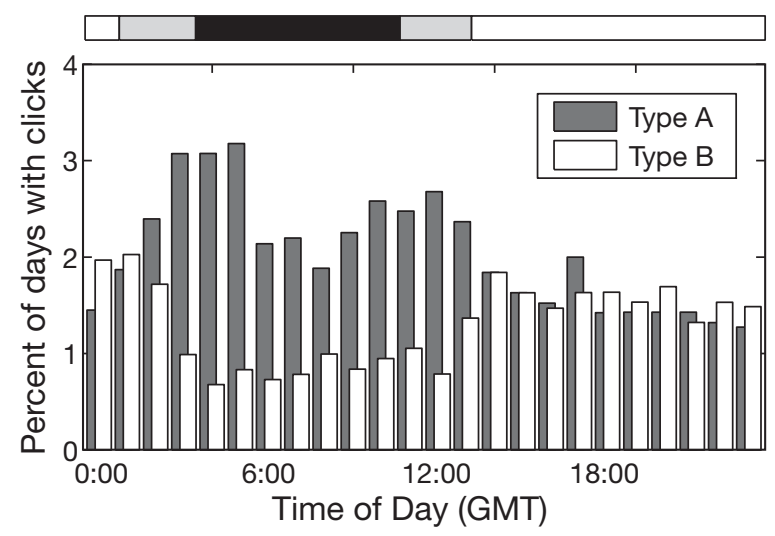

Fig. 5. Diel patterns of Pacific white-sided dolphin echolocation click bouts combined across the 6 High-frequency Acoustic Recording Package locations. Vertical bars represent the percent of days that have clicks present in $1 \mathrm{~h}$ time bins. Horizontal bar at top indicates periods of light (white), darkness (black) or periods that may be light or dark depending on time of year (light gray) with an increase around sunset, followed by a slight decrease during the middle of the night. Click bout occurrence increased again before dawn and then occurred at a lower level throughout the day (Fig. 5). The Point Conception and San Nicholas Basin sites appear to contribute the most to this diel pattern, while other sites exhibited greater variability. Statistical comparisons of the variability in click bout occurrence and click rate between day and night reveal that click bouts occurred significantly more often and click rates were significantly higher at night than during the day (ANOVA, click bout occurrence: $F=24.4$, p $<0.001$, $\mathrm{N}=316$; click rate: $F=35.7, \mathrm{p}<0.001, \mathrm{~N}=272$ ) (Fig. 6).

A distinct diel pattern was also evident for the hourly occurrence of Pacific white-sided Type B echolocation clicks bouts at the 2 southern sites. However, the hourly occurrence pattern was opposite of that found for Type A clicks, showing a more consistent pattern throughout the day with a decrease during the night (Fig. 5). Similarly, comparisons of the variability in click bout occurrence and click rate between day and night indicate that click bouts occurred significantly more often and click rates were significantly higher during the day than at night (ANOVA, click bout occurrence: $F=10.8, \mathrm{p}=0.001, \mathrm{~N}=130$; click rate: $F=$ 5.6, $\mathrm{p}<0.018, \mathrm{~N}=111$ ) (Fig. 6).

\section{Seasonal and annual variation}

Occurrence per week of Pacific white-sided dolphin Type A click bouts exhibited seasonal, annual and sitespecific variability (Fig. 7a). Results of ANOVA analyses indicate that site, year and the interaction between season and site were significant sources of variability in mean occurrence (Table 3). Tamhane's T2 post hoc analyses demonstrate that click bouts occurred significantly more often at San Clemente Island than all other sites and significantly more often at Point Conception than at the remaining 2 sites. Additionally, click bouts were identified significantly more often in 2007 than 2005. The interaction effects of season and site indicate that clicks were identified most frequently during the winter at Santa Catalina Island and in the Santa Barbara Channel, during fall and winter at San Clemente Island and during spring at Point Conception.

Similarly, occurrence per week of Pacific whitesided dolphin Type B click bouts also exhibited seasonal, annual and site-specific variability (Fig. 7b). Results of ANOVA analyses indicate that the main factors of season and site as well as the interaction effects of site $\times$ year, site $\times$ season, year $\times$ season and year $\times$ site $\times$ season were all significant sources of variability in mean occurrence (Table 4). Tamhane's T2 post hoc analyses demonstrate that click bouts 

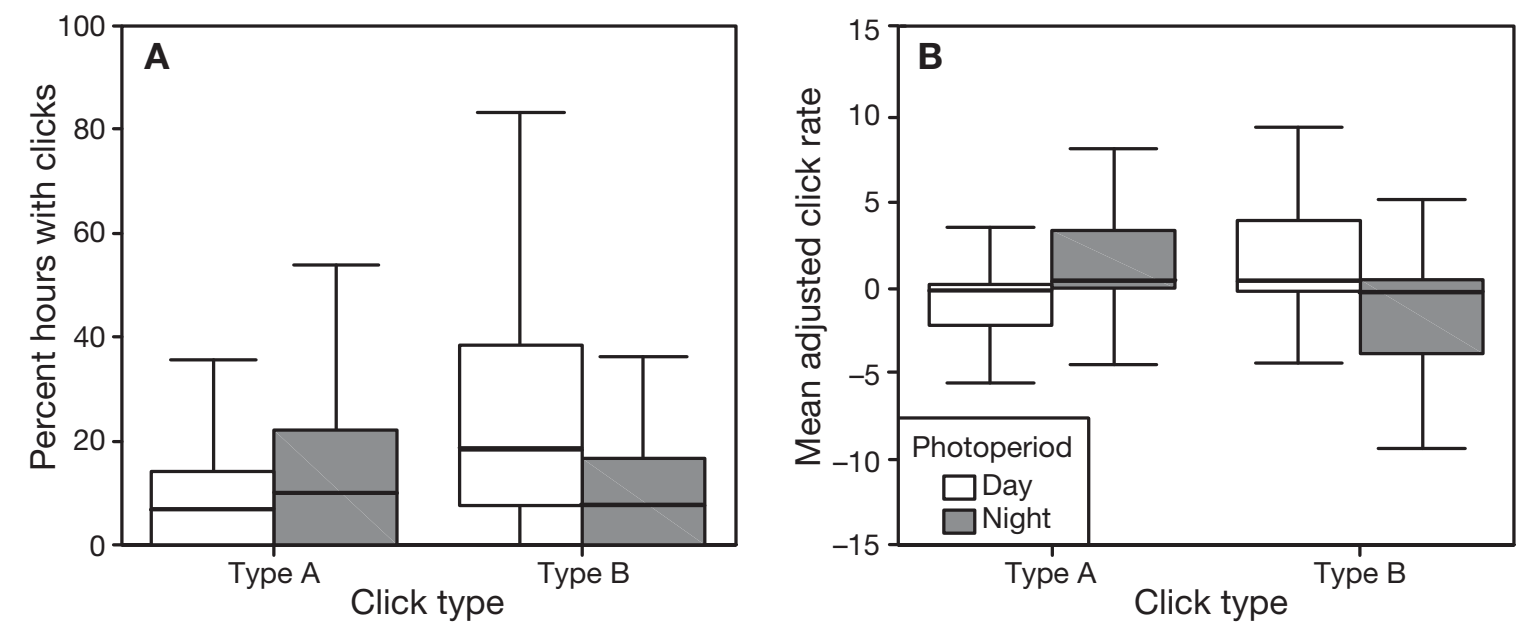

Fig. 6. Variation in Pacific white-sided dolphin Types A and B (A) click bout occurrence and (B) daily click rate anomaly between day and night periods. Central lines represent median value, boxes contain 25 th to 75 th percentiles and whiskers contain 5 th to 95th percentiles of data. Click bout occurrence and click rate are both significantly higher during night than day for Type A clicks but the opposite for Type B clicks
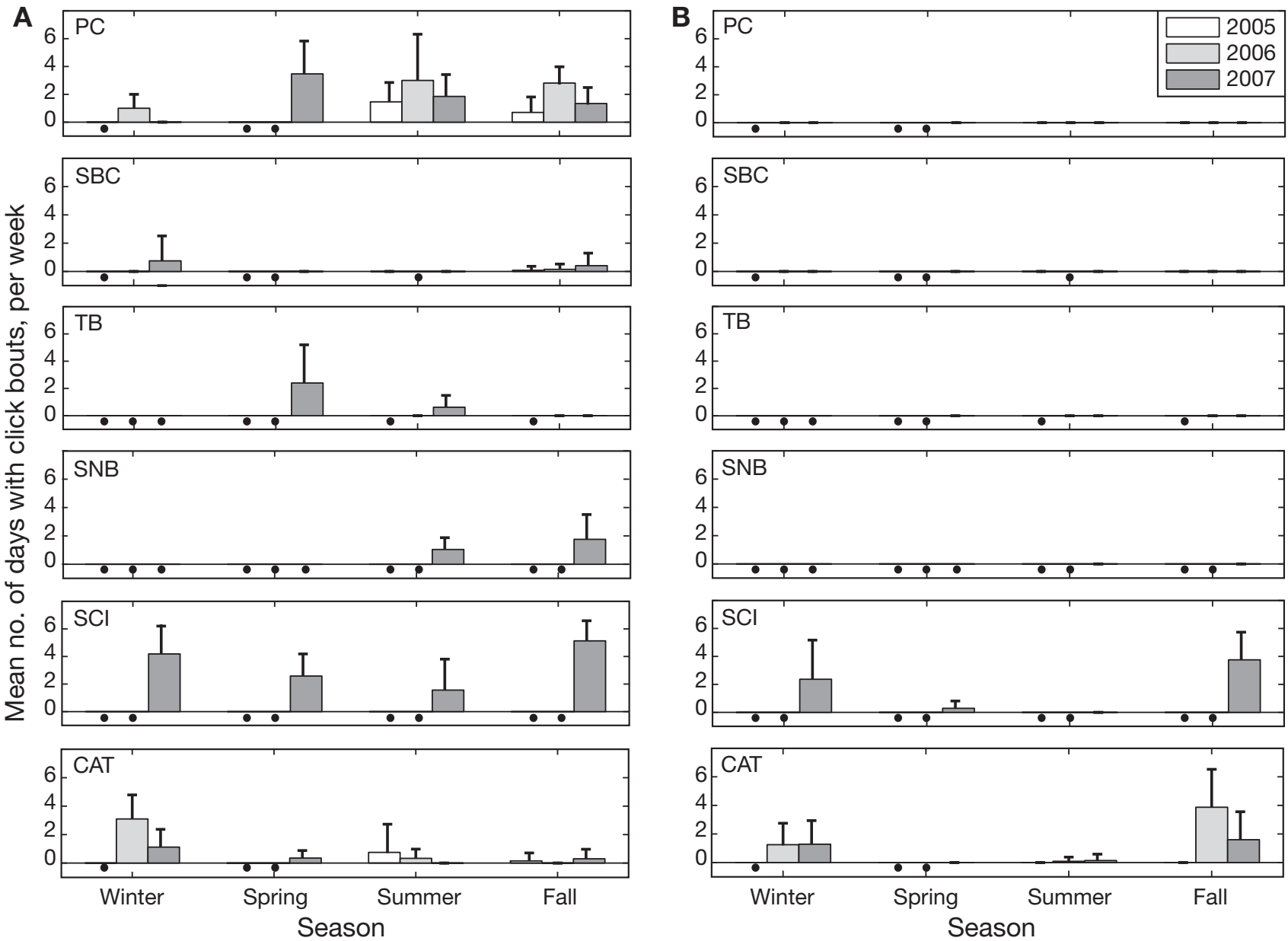

Fig. 7. Seasonal and annual variation of Pacific white-sided dolphin (A) Type A and (B) Type B click bouts across the 6 Highfrequency Acoustic Recording Package sites. Bar shading indicates year. Error bars are \pm SD. Black dots below zero indicate no data were available in that season and year. See Fig. 1 for site abbreviations 
Table 3. Results of 3-way ANOVA for seasonal, annual and site effects on Pacific white-sided dolphin Type A click bout occurrence. Asterisks indicate significant effects $(p<0.05)$. The main effects of Site and Year and the interaction effects of Season $\times$ Site all significantly influenced the occurrence of Type A click bouts

\begin{tabular}{|lccccc|}
\hline Source & Type IV SS & df & MS & $F$ & $\mathrm{p}$ \\
\hline Corrected model & 513.6 & 29 & 17.7 & 10.2 & 0.000 \\
Intercept & 301.2 & 1 & 301.2 & 174.2 & 0.000 \\
Season & 2.1 & 3 & 0.7 & 0.4 & 0.745 \\
Site & 207.1 & 3 & 69.0 & 39.9 & $0.000^{*}$ \\
Year & 11.2 & 2 & 5.6 & 3.2 & $0.041^{*}$ \\
Season $\times$ Site & 124.2 & 9 & 13.8 & 8.0 & $0.000^{*}$ \\
Season $\times$ Year & 1.9 & 3 & 0.6 & 0.4 & 0.783 \\
Site $\times$ Year & 13.0 & 4 & 3.2 & 1.9 & 0.115 \\
Season $\times$ Site $\times$ Year & 7.9 & 5 & 1.6 & 0.9 & 0.476 \\
Error & 389.1 & 225 & 1.7 & & \\
Total & 1260.7 & 255 & & & \\
Corrected total & 902.7 & 254 & & & \\
\hline
\end{tabular}

Table 4. Results of 3-way ANOVA for seasonal, annual and site effects on Pacific white-sided dolphin Type B click bout occurrence. Asterisks indicate significant effects $(p<0.05)$. The main effects of Season and Site, and the interaction effects of Season $\times$ Site, Season $\times$ Year, Site $\times$ Year and Season $\times$ Site $\times$ Year all significantly influenced the occurrence of Type B click bouts

\begin{tabular}{|lccccc|}
\hline Source & Type IV SS & df & MS & $F$ & $\mathrm{p}$ \\
\hline Corrected model & 324.0 & 29 & 11.2 & 10.1 & 0.000 \\
Intercept & 48.3 & 1 & 48.3 & 43.6 & 0.000 \\
Season & 38.3 & 3 & 12.8 & 11.5 & $0.000^{*}$ \\
Site & 55.5 & 3 & 18.5 & 16.7 & $0.000^{*}$ \\
Year & 6.1 & 2 & 3.0 & 2.7 & 0.067 \\
Season $\times$ Site & 50.2 & 9 & 5.6 & 5.0 & $0.000^{*}$ \\
Season $\times$ Year & 11.0 & 3 & 3.7 & 3.3 & $0.021^{*}$ \\
Site $\times$ Year & 12.0 & 4 & 3.0 & 2.7 & $0.031^{*}$ \\
Season $\times$ Site $\times$ Year & 18.7 & 5 & 3.7 & 3.4 & $0.006^{*}$ \\
Error & 249.1 & 225 & 1.1 & & \\
Total & 649.5 & 255 & & & \\
Corrected total & 573.1 & 254 & & & \\
\hline
\end{tabular}

occurred significantly more often at San Clemente Island than at all other sites and significantly more often at Santa Catalina Island than at the 2 northern sites that had no Type B click bout detections. Additionally, click bouts were detected significantly more often during fall and winter than during spring and summer. The low occurrence of detections during 2005 and their complete absence at the 2 northern sites appear to be the main reason that all interaction effects (site $\times$ year, site $\times$ season, year $\times$ season and year $\times$ site $\times$ season) were significant. Fall and winter peaks in seasonal occurrence were evident at both Santa Catalina and San Clemente Island sites across 2006 and 2007.

\section{DISCUSSION}

\section{Comparison of click type usage}

The present study shows that distinct geographical and temporal usage patterns exist for the 2 distinct Pacific white-sided dolphin echolocation click types: (1) Type A clicks were heard throughout the region while Type B clicks were only heard at the 2 southern inshore sites; (2) Type A clicks generally exhibited increased activity at night, although some site-specific variability exists, while Type B clicks exhibited increased activity during the day; and (3) Type A clicks exhibited a peak in occurrence in spring at the northern offshore site, a peak during winter at the most inshore northern and southern sites and a peak during fall/winter at the remaining southern inshore site, while Type B clicks exhibited a peak seasonal occurrence during fall/winter at both southern inshore sites.

The biological significance of the 2 Pacific whitesided dolphin click types is unknown and could be a result of adaptive control or constrained by morphological variations. Adaptive control of frequency- and source-level characteristics related to target or prey detection has been described in a variety of odontocete species in both experimental and wild settings (Moore \& Pawloski 1990, Au et al. 1995, Houser et al. 1999, Simon et al. 2007, DeRuiter et al. 2009). This suggests the possibility that Pacific white-sided dolphins may also be able to voluntarily adjust the frequency spectra of their clicks. However, to date, the presence of spectral banding patterns described for the 2 Pacific whitesided dolphin click types has only been reported in one other species, Risso's dolphins (Soldevilla et al. 2008), and it is unknown how clicks with these patterns are produced or whether adaptive control over their production is possible. Soldevilla et al. (2008) hypothesized that clicks with these patterns may be constrained by unique skull and melon morphology, explaining the high consistency within a species and supporting the hypothesis that the 2 click types may be related to the 2 populations of Pacific white-sided dolphins whose skull dimensions are among the major distinguishing morphological characteristics. The lack of knowledge on click production capabilities in these animals presents a challenge to identifying the biological significance of the 2 click types.

The spatial and temporal differences between occurrence of the 2 Pacific white-sided dolphin click types reported in the present study can be used to examine a suite of hypotheses about the biological significance of the 2 click types. Possible hypotheses to explain interschool differences in click type production include differences in group size, group composition (population-, age- or gender-specific), behavior state or prey type 
(Soldevilla et al. 2008). The described spectral features are both consistent within click types and distinct between types. It is unlikely that group size, group composition stratified by gender or age and behavioral differences would result in only 2 distinct acoustic patterns and the observed spatial separation in usage. Geographic ranges of Pacific white-sided dolphin populations and their prey might exhibit the described spatial patterns and, therefore, hypotheses about population composition and prey type differences deserve further consideration.

If click type usage varies with prey type, the biological significance of click types may be represented by prey differences such as 2 distinct size classes (e.g. large and small prey), compositional differences in prey (e.g. acoustically reflective differences between squid and fish, or between fish with swim bladders and those without) or behavioral differences (e.g. schooling or non-schooling prey). Pacific white-sided dolphins typically feed on a continuous range of prey sizes (10 to $60 \mathrm{~cm}$ ) across species (Fitch \& Brownell 1968, Heise 1997), so prey size variations are unlikely to result in 2 distinct click types. Mesopelagic prey, including squid and myctophids, do not school or contain swim bladders, while epipelagic schooling fish prey all contain highly reflective swim bladders (Holliday 1972, Mais 1974, Diachok 2001). Diel differences in click type activity support hypotheses that the 2 click types represent foraging on either of these 2 groups (with or without swim bladders). Click type A, which occurred most often at night, may be used when foraging on mesopelagic squid and myctophids, which are more accessible at night when they migrate to shallower waters. Similar nighttime foraging on diel vertically migrating squid and myctophids has been found for Hawaiian spinner dolphins Stenella longirostris and dusky dolphins Lagenorhynchus obscurus (Benoit-Bird \& Au 2003, Benoit-Bird et al. 2004), and the diel patterns of Type A click production are very similar to those found for Risso's dolphins (Soldevilla et al. 2010), which feed exclusively on squid. Conversely, click Type $B$, which occurred more frequently during the day, may be used when foraging on epipelagic fish which may be more accessible when grouped in schooling formation during the day. While diel patterns support the prey difference hypothesis for click type significance, prey type hypotheses alone do not explain the geographic differences in click type usage, as all major Pacific white-sided dolphin prey types in the SCB are generally distributed evenly throughout the region (Okutani \& McGowan 1969, Mais 1974, Agostini et al. 2006). Additionally, if the dolphins have the ability to modify their click structure based on prey type, it seems likely that more click types should exist given prey variability. Finally, whether the slight differences in frequency between the 2 click types is acoustically significant in prey detection is unknown and should be investigated further.

Alternatively, if click types are population-specific, the spatial seasonal usage patterns would reflect distribution and seasonal movement patterns of the 2 Pacific white-sided dolphins populations described by Walker et al. (1986) and Lux et al. (1997) which overlap in the SCB. Results presented here would indicate that Type A clicks, which were heard throughout the region, represent the California/Oregon/Washington population, while the Type B clicks, which were only heard in the southern inshore region, would represent the Baja California population (Fig. 1). A comparison of the seasonal patterns of Type A clicks suggest northward offshore movements in spring and summer and southward inshore movements during fall and winter with animals mostly out of the study region during summer. These results are similar to the described northward or offshore movements during summer/fall and southward or inshore movements during winter/ spring from visual surveys (Brown \& Norris 1956, Norris \& Prescott 1961, Roest 1970, Dohl et al. 1983, Green et al. 1992, Black 1994, Forney \& Barlow 1998). However, the present study could not determine where the dolphins go when they are not in this region and, therefore, could not distinguish whether they move to central California or as far north as Oregon/Washington. Examination of seasonal patterns of Type B clicks suggests that the southern inshore sites represent the northern extent of the of the Baja California population range and indicates northward movements during fall and winter and southward movements into Mexican waters during spring and summer. These results are similar to the described winter/spring northward and summer/fall southward movements between southern California and Baja California from visual surveys (Leatherwood et al. 1984). Offshore movements of animals producing Type B calls cannot be excluded during winter or spring when minimal sampling occurred at the southern offshore sites.

Neither the prey type- or population-specific hypotheses could be excluded based on spatial or temporal differences in click type occurrence in the SCB. Seasonal and spatial patterns support the population-specific hypothesis, while diel patterns support the prey type hypothesis, though spatial patterns do not. The most parsimonious explanation for geographical and temporal differences between the 2 click types may be that both population and prey types are important, such that morphological differences between the 2 populations result in production of different click types and, coincidentally, the 2 populations have different prey preferences which exhibit differences in diel availability. This would suggest that southern Type B 
dolphins are foraging on daytime schooling epipelagic fish, while northern Type A dolphins are foraging mainly on diel migrating prey such as squid and myctophids, with some daytime foraging on schooling fish at some sites. Prey analysis studies do not distinguish between these 2 populations, so actual differences in feeding that may affect diel behavior remain unknown. Future studies should incorporate concurrent acoustic, genetic and prey sampling to test these hypotheses.

\section{Limitations}

When considering the diel behavior of highly mobile species such as dolphins, it is unclear whether a lack of acoustic detections represents absence of the dolphins from the study site or presence of non-vocalizing animals (e.g. Mackenzie et al. 2006). Dolphins are capable of moving into and out of a study site within a day, as shown by visual surveys of spinner dolphins off Hawaii that exhibit diel movements between inshore resting areas during the day to offshore feeding zones at night (Norris et al. 1994, Benoit-Bird \& Au 2003). Therefore, the diel variation in occurrence of Pacific white-sided dolphin clicks could either represent movements out of the area during periods of low acoustic activity and movements into the area during periods of high acoustic activity, or changes in echolocation activity as a function of varying behavior state. Increased echolocation has been associated with foraging and traveling (Norris et al. 1994, Barrett-Lennard et al. 1996, Van Parijs \& Corkeron 2001, Nowacek 2005). The diel variability in Type A click activity between sites may indicate that the dolphins change foraging location depending on diel availability of prey at each site. The development of compact acoustic tags (e.g. Johnson \& Tyack 2003, Akamatsu et al. 2005), similar to those used on larger whales, may provide more definitive answers.

Factors which may affect acoustic detection ranges and, therefore, the probability of detecting calling animals include directionality of the sound source, distance from hydrophone, sound propagation conditions and acoustic masking. Typical delphinid echolocation click detection ranges are thought to be $1 \mathrm{~km}$ (Richardson et al. 1995), though recent evidence shows on-axis beaked whale clicks, whose bandwidth matches our frequency range of interest (25 to $50 \mathrm{kHz}$ ), may be detected as far as 4 to $6.5 \mathrm{~km}$ (Ward et al. 2008, Zimmer et al. 2008). Echolocation clicks are highly directional (Au 1993), which has a strong effect on detection range (e.g. Zimmer et al. 2008), and variability in animals' dive depth or instrument depth could explain some of the described diel or site-specific variability if dolphin echolocation beams are rarely directed downward.
Dolphins typically scan their environment in both the horizontal and vertical planes, so this may not be an issue; however, studies that examine how click detectability varies with depth, e.g. on a vertical hydrophone array, could help answer this question. Sound propagation conditions may vary across sites and seasons, leading to spatial and seasonal variability in detection probability; however, conditions are typically downward refracting in the SCB across seasons and sites. Examination of other click types (e.g. Risso's dolphins, Soldevilla et al. 2010) indicates different seasonal and site-specific patterns for other species and does not indicate a strong bias for any site or season. Additionally, at the frequencies used for echolocation, attenuation severely limits detection range; therefore, the potential for significant variation owing to seasonal variations in propagation conditions is reduced. Vessels, sonars, other animals, rain, wind and waves may produce sounds that mask the echolocation click of our chosen species, so it is important to consider seasonality in these sources. Preliminary analyses indicate that vessel noise is consistent throughout the year at all sites except Santa Catalina Island, where there is an increase in occurrence during the summer (MaySeptember), while wind and rain noise within the frequency band of clicks occurs minimally throughout the year. A more thorough investigation of seasonal variation related to these noise sources is the topic of another study.

Several potential biases of this click detection algorithm and its effects on the diel click rate analysis are worth considering. Factors that could bias the click counts low include: (1) the presence of many low amplitude clicks that did not exceed the thresholds; (2) during periods of intense clicking (multiple high amplitude overlapping click trains), the mean spectral intensity of the surrounding $3 \mathrm{~s}$ of data used for spectral-mean-subtraction would be relatively high, resulting in some high amplitude clicks being missed by the detector; and (3) during periods with rapid click trains or click trains from multiple individuals in which the apparent interclick interval was greater than $15 \mathrm{~ms}$, only one click was chosen per $15 \mathrm{~ms}$. Additional biases could be caused by misclassification of click bouts in the LTSAs. As noted above, if multiple species or click types were detected during a Pacific white-sided dolphin click bout, and it was apparent in the LTSAs, these data were classified as mixed group and were not included in the analysis, biasing the individual Pacific white-sided click counts low. However, if multiple groups were present and clicking, but the click bout was classified as one Pacific white-sided dolphin click type, this would cause the click counts to be biased high for that click type by including clicks from all groups. This bias is not expected to be large, as 
LTSA analysis is more sensitive to the presence of low amplitude clicks than the detector; if other species or click types were present but not distinguishable in the LTSA, the individual clicks would rarely be counted by the automatic detector. The presence of intense clicking and/or rapid or overlapping click trains were likely to be the most influential of these biases, resulting in lower detected click rates during periods with many clicks. These biases would result in lower reported click rates during periods with the highest actual click rates, reducing overall click rate variability; therefore, comparisons of diel click rate patterns are conservative.

\section{CONCLUSIONS}

The seasonal occurrence of Pacific white-sided dolphin Type A clicks at northern sites in the SCB during spring and at southern sites during fall and winter, as well as the occurrence of Type B clicks at only the southern inshore sites during fall and winter, supports the hypothesis that these 2 click types represent the California/Oregon/Washington and the Baja California populations of Pacific white-sided dolphins that are known to overlap in range within the SCB. Diel variability in echolocation activity also differed between click types, with greater nighttime activity for Type A clicks and greater daytime activity for Type B clicks, supporting hypotheses of differences in prey type which exhibit different diel availability to foraging dolphins. It is possible that both hypotheses are valid, such that the 2 populations specialize on different prey types. Future studies should test the acoustic separation of populations by both extending sampling into the northern and southern ranges of these populations, where mixing does not occur, and conducting combined genetic and acoustic field sampling. Future stomach contents analyses should indicate time and location of collection of Pacific white-sided dolphins and should preferably identify the dolphin population genetically to investigate the mechanism behind these differences.

Acoustic coverage at offshore sites in the present study did not include a long enough duration to examine the hypothesis about inshore-offshore seasonal movements of the populations, nor was a northern extent of migrations available to determine if animals occupying the SCB in fall/winter are moving to central California, Oregon/Washington or offshore during the spring, summer and early fall. Extending the spatial coverage of long-term acoustic monitoring to include these northern and offshore regions would help answer these questions. Similarly, the extension of monitoring to the south could advance knowledge on the seasonal movements of the Baja California population. Finally, interannual and interdecadal variability in abundance and movement patterns have been described in previous studies of Pacific white-sided dolphins; however, the shorter durations of the presented time series preclude the in-depth examination of interannual and interdecadal changes. These time series are ongoing and have the potential to answer such questions in the future.

Acknowledgements. The authors thank all the personnel who were involved in instrument development, deployment, recovery and data acquisition including: S. Baumann, H. Basset, C. Berchock, G. Campbell, G. Crocker, C. Garsha, M. Gassmann, E. Henderson, B. Hurley, M. McKenna, L. Munger, E. Oleson, E. Roth, N. Rubio and L. Williams. J. Barlow, S. Baumann, D. Checkley, B. Cornuelle, E. Henderson, L. Munger, E. Oleson, B. Rao and M. Roch provided insightful discussions and/or constructive critique of early versions of the manuscript. We thank the Achievement Rewards for College Scientists (ARCS) Foundation, Los Angeles chapter, for supporting M.S.S., and F. Stone and E. Young for supporting our work through CNO-N45.

\section{LITERATURE CITED}

Agostini VN, Francis RC, Hollowed AB, Pierce SD, Wilson C, Hendrix AN (2006) The relationship between Pacific hake (Merluccius productus) distribution and poleward subsurface flow in the California Current System. Can J Fish Aquat Sci 63:2648-2659

Akamatsu T, Matsuda A, Suzuki S, Wang D and others (2005) New stereo acoustic data logger for free-ranging dolphins and porpoises. Mar Technol Soc J 39:3-9

Au WWL (1993) The sonar of dolphins. Springer-Verlag, New York

Au WWL, Pawloski JL, Nachtigall PE, Blonz M, Gisner RC (1995) Echolocation signals and transmission beam pattern of a false killer whale (Pseudorca crassidens). J Acoust Soc Am 98:51-59

Barlow J, Forney KA (2007) Abundance and population density of cetaceans in the California Current ecosystem. Fish Bull 105:509-526

Barrett-Lennard LG, Ford JKB, Heise KA (1996) The mixed blessing of echolocation: differences in sonar use by fisheating and mammal-eating killer whales. Anim Behav 51: 553-565

Benoit-Bird KJ, Au WWL (2003) Prey dynamics affect foraging by a pelagic predator (Stenella longirostris) over a range of spatial and temporal scales. Behav Ecol Sociobiol 53:364-373

> Benoit-Bird KJ, Wursig B, McFadden CJ (2004) Dusky dolphin (Lagenorhynchus obscurus) foraging in two different habitats: active acoustic detection of dolphins and their prey. Mar Mamm Sci 20:215-231

> Benson SR, Croll DA, Marinovic BB, Chavez FP, Harvey JT (2002) Changes in the cetacean assemblage of a coastal upwelling ecosystem during El Niño 1997-98 and La Niña 1999. Prog Oceanogr 54:279-291

Black NA (1994) Behavior and ecology of Pacific white-sided dolphins (Lagenorhynchus obliquidens) in Monterey Bay, California. MS thesis, San Francisco State University 
Brown DH, Norris KS (1956) Observations of captive and wild cetaceans. J Mammal 37:311-326

Carretta JV (2004) US Pacific marine mammal stock assessments: 2003. NOAA, National Marine Fisheries Service, Southwest Fisheries Science Center, La Jolla, CA

DeRuiter SL, Bahr A, Blanchet MA, Hansen SF and others (2009) Acoustic behaviour of echolocating porpoises during prey capture. J Exp Biol 212:3100-3107

Diachok O (2001) Interpretation of the spectra of energy scattered by dispersed anchovies. J Acoust Soc Am 110: $2917-2923$

Dohl TP, Guess RC, Duman ML, Helm RC (1983) Cetaceans of central and northern California, 1980-1983: status, abundance, and distribution. Pacific OCS Region Minerals Management Service, Santa Cruz, CA

Fitch JE, Brownell RL (1968) Fish otoliths in cetacean stomachs and their importance in interpreting feeding habits. J Fish Res Board Can 25:2561-2574

Forney KA, Barlow J (1998) Seasonal patterns in the abundance and distribution of California cetaceans, 1991-1992. Mar Mamm Sci 14:460-489

Garson GD (2008) Univariate GLM, ANOVA, and ANCOVA. Statnotes: topics in multivariate analysis. Available at http://www2.chass.ncsu.edu/garson/pa765/statnote.htm

Green G, Brueggeman JJ, Grotefendt RA, Bowlby CE, Bonnell ML, Balcomb KT III (1992) Cetacean distribution and abundance off Oregon and Washington. US Department of the Interior, Los Angeles, CA

Heise KA (1997) Diet and feeding behaviour of Pacific whitesided dolphins (Lagenorhynchus obliquidens) as revealed through the collection of prey fragments and stomach content analyses. Rep Int Whaling Comm 47:807-815

Holliday DV (1972) Resonance structure in echoes from schooled pelagic fish. J Acoust Soc Am 51:1322-1332

Houser DS, Helweg DA, Moore PW (1999) Classification of dolphin echolocation clicks by energy and frequency distributions. J Acoust Soc Am 106:1579-1585

Johnson MP, Tyack PL (2003) A digital acoustic recording tag for measuring the response of wild marine mammals to sound. IEEE J Oceanic Eng 28:3-12

Leatherwood S, Evans WE (1979) Some recent uses and potentials of radio-telemetry in field studies of cetaceans. In: Winn HE, Olla BI (eds) Behavior of marine animals, Vol 3. Plenum Press, New York, p 1-31

Leatherwood S, Reeves RR, Perrin WF, Evans WE (1982) Whales, dolphins and porpoises of the eastern North Pacific and adjacent Arctic waters. Dover Publications, Mineola, NY

Leatherwood S, Reeves RR, Bowles AE, Stewart BS, Goodrich KR (1984) Distribution, seasonal movements, and abundance of Pacific white-sided dolphins in the eastern North Pacific. Sci Rep Whales Res Inst 35:129-157

Lockyer C (1981) Estimates of growth and energy budget for the sperm whale, Physeter catodon. In: Gordon Clark J (ed) Mammals in the seas, Vol 3: general papers and large cetaceans. FAO, Rome, p 489-504

Lux CA, Costa AS, Dizon AE (1997) Mitochondrial DNA population structure of the Pacific white-sided dolphin. Rep Int Whaling Comm 47:645-652

Mackenzie DI, Nichols JD, Royle JA, Pollock KH, Bailey LL, Hines JE (2006) Occupancy estimation and modeling: inferring patterns and dynamics of species occurrence. Academic Press, San Diego, CA

Mais KF (1974) Pelagic fish surveys in the California Current. Fish Bull 162:1-78

Moore PWB, Pawloski DA (1990) Investigations on the control of echolocation pulses in the dolphin (Tursiops truncatus).
In: Thomas J, Kastelein R (eds) Sensory abilities of cetaceans: laboratory and field evidence. Plenum Press, New York, p 305-316

> Morton A (2000) Occurrence, photo-identification and prey of Pacific white-sided dolphins (Lagenorhynchus obliquidens) in the Broughton Archipelago, Canada 1984-1998. Mar Mamm Sci 16:80-93

Norris KS, Prescott JH (1961) Observations on Pacific cetaceans of Californian and Mexican waters. Univ Calif Publ Zool 63:291-402

Norris KS, Wursig B, Wells RS, Wursig M (1994) The Hawaiian spinner dolphin. University of California Press, Berkeley, CA

> Nowacek DP (2005) Acoustic ecology of foraging bottlenose dolphins (Tursiops truncatus), habitat-specific use of three sound types. Mar Mamm Sci 21:587-602

Okutani T, McGowan JA (1969) Systematics, distribution, and abundance of the epiplanktonic squid (Cephalopoda, Decapoda) larvae of the California Current, April, 1954-March, 1957. Scripps Institution of Oceanography, La Jolla, CA

Richardson W, Greene CJ, Malme C, Thomson D (1995) Marine mammals and noise. Academic Press, San Diego, CA

Roest AI (1970) Kogia simus and other cetaceans from San Luis Obispo County, California. J Mammal 51:410-417

Shane SH (1994) Occurrence and habitat use of marine mammals at Santa Catalina Island, California from 1983-91. Bull South Calif Acad Sci 93:13-29

Simon M, Wahlberg M, Miller LA (2007) Echolocation clicks from killer whales (Orcinus orca) feeding on herring ( $\mathrm{Clu}$ pea harengus). J Acoust Soc Am 121:749-752

Smith GJ, Gaskin DE (1974) The diet of harbor porpoises (Phocoena phocoena) in coastal waters of eastern Canada, with special reference to the Bay of Fundy. Can J Zool 52:777-782

Soldevilla MS (2008) Risso's and Pacific white-sided dolphins in the Southern California Bight: using echolocation clicks to study dolphin ecology. PhD dissertation, University of California, San Diego, CA

Soldevilla MS, Henderson EE, Campbell GS, Wiggins SM, Hildebrand JA, Roch MA (2008) Classification of Risso's and Pacific white-sided dolphins using spectral properties of echolocation clicks. J Acoust Soc Am 124:609-624

Soldevilla MS, Wiggins SM, Hildebrand JA (2010) Spatial and temporal patterns of Risso's dolphin echolocation in the Southern California Bight. J Acoust Soc Am 127: 124-132

Stroud RN, Fiscus CH, Kajimura H (1981) Food of the Pacific white-sided dolphin, Lagenorhynchus obliquidens, Dall's porpoise, Phocoenoides dalli, and northern fur seal, Callorhinus ursinus, off California and Washington. Fish Bull 78:951-959

US Naval Observatory (2008) Astronomical Applications Department. Available at http://aa.usno.navy.mil

> Van Parijs SM, Corkeron PJ (2001) Vocalizations and behaviour of Pacific humpback dolphins Sousa chinensis. Ethology 107:701-716

Walker WA, Leatherwood S, Goodrick KR, Perrin WF, Stroud RK (1986) Geographic variation and biology of the Pacific white-sided dolphin, Lagenorhynchus obliquidens, in the north-eastern Pacific. In: Bryden MM, Harrison R (eds) Research on dolphins. Clarendon Press, Oxford, p 441-465

Ward J, Morrissey R, Moretti D, DiMarzio N and others (2008) Passive acoustic detection and localization of Mesoplodon densirostris (Blainville's beaked whale) vocalizations 
using distributed bottom-mounted hydrophones in conjunction with a digital tag (DTag) recording. Can Acoust 36:60-66

Welch PD (1967) The use of fast Fourier transform for the estimation of power spectra: a method based on time averaging over short, modified periodograms. IEEE Trans Audio Electroacoust 15:70-73

Wiggins SM, Hildebrand JA (2007) High-frequency Acoustic Recording Package (HARP) for broad-band, long-term

Editorial responsibility: Peter Corkeron,

Ithaca, New York, USA marine mammal monitoring. Symposium on Underwater Technology and Workshop on Scientific Use of Submarine Cables and Related Technologies, 17-20 Apr 2007. IEEE, Tokyo, p 551-557

Zar JH (1999) Biostatistical analysis. Prentice Hall, Upper Saddle River, NJ

- Zimmer WMX, Harwood J, Tyack PL, Johnson MP, Madsen PT (2008) Passive acoustic detection of deep-diving beaked whales. J Acoust Soc Am 124:2823-2832

Submitted: October 26, 2009; Accepted: January 20, 2010

Proofs received from author(s): March 19, 2010 